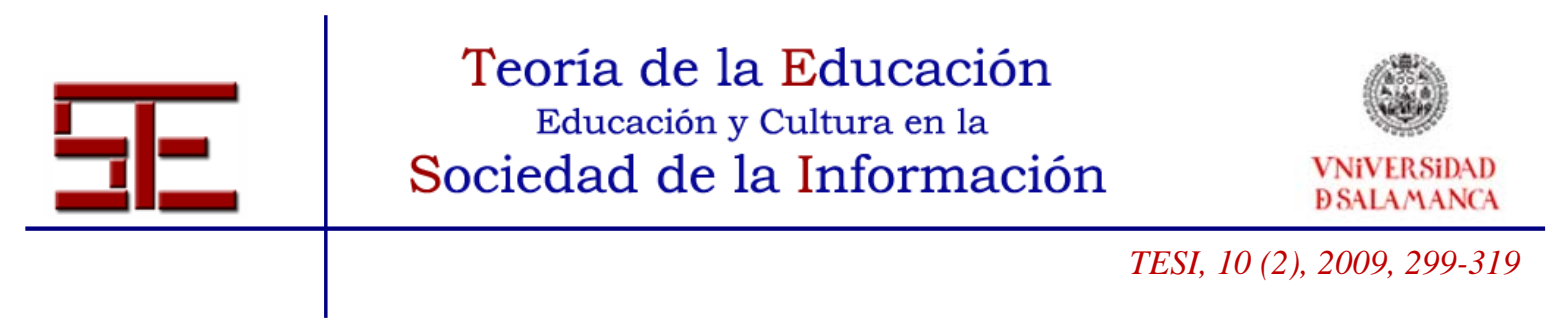

\title{
CONSIDERACIONES TEÓRICAS SOBRE EL CONCEPTO CALIDAD DE VIDA EN LA SOCIEDAD DE LA INFORMACIÓN
}

Resumen: El objetivo del presente artículo se centra en obtener una definición aproximada del concepto calidad de vida y en presentar las dimensiones y variables que dan forma a su contenido, valorando las influencias y los efectos provocados por la aparición de las nuevas tecnologías de la información y la comunicación en el bienestar de las personas. La distribución discriminatoria e injusta de las nuevas tecnologías sobre el territorio podría incidir negativamente en la calidad de vida de muchas comunidades, aumentando las desigualdades y los desequilibrios socioespaciales.

Palabras clave: Calidad de Vida, Sociedad de la Información, TIC, Brecha Digital

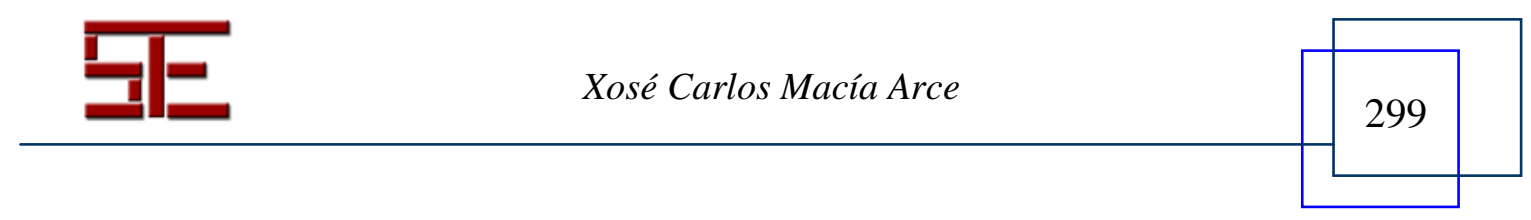




\section{THEORETICAL CONSIDERATIONS ON THE CONCEPT QUALITY OF LIFE IN THE INFORMATION SOCIETY}

Abstract: The aim of this paper focuses on obtaining an approximate definition of the concept quality of life and to present the dimensions and variables that shape their content, evaluating the influences and effects caused by the emergence of new information technologies and communication in people's welfare. Discriminatory and unfair distribution of new technologies on the territory could affect the quality of life of many communities, increasing spatial inequalities.

Key words: Quality of Life, Information Society, ICT, Digital Fracture.

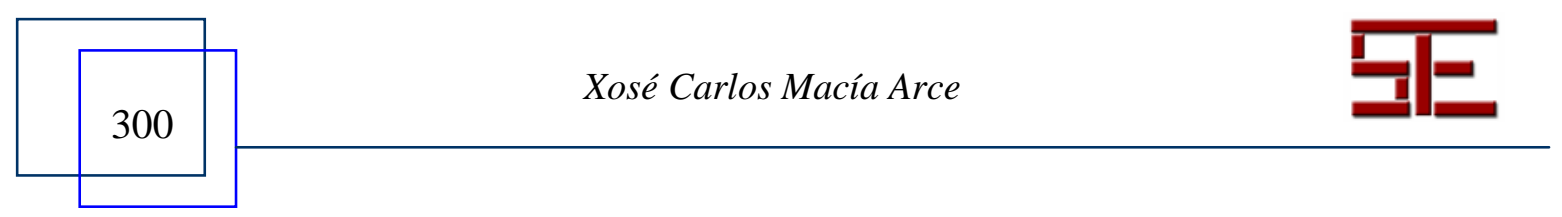




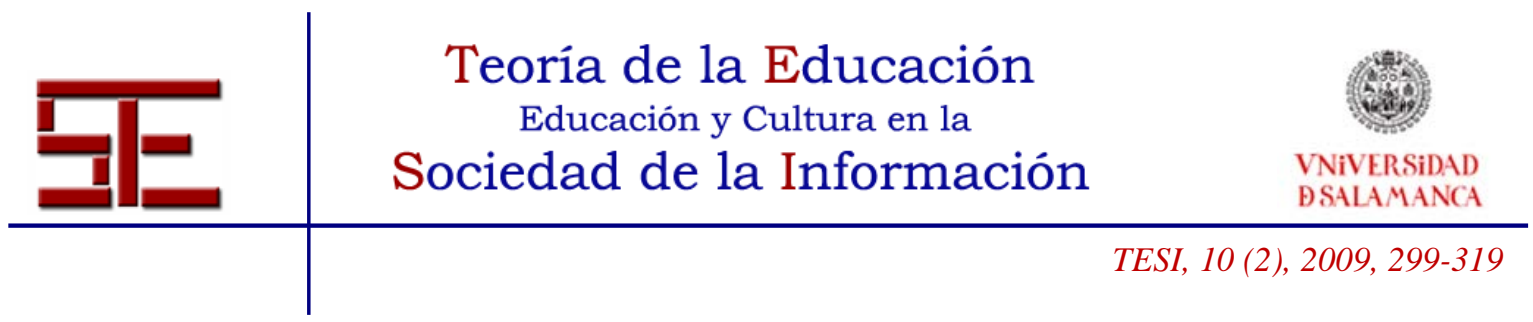

\section{CONSIDERACIONES TEÓRICAS SOBRE EL CONCEPTO CALIDAD DE VIDA EN LA SOCIEDAD DE LA INFORMACIÓN}

Xosé Carlos Macía Arce

carlos.macia@usc.es

Grupo de Investigación Sociedad, Tecnología y Territorio GIST.

Universidad de Santiago de Compostela.

\section{1.- INTRODUCCIÓN}

El objetivo del presente artículo se centra en obtener una definición aproximada del concepto calidad de vida y, por otra parte, en presentar las dimensiones y variables que dan forma a su contenido, valorando las influencias y los efectos, positivos y negativos, provocados por la entrada reciente en la Sociedad de la Información y la consiguiente aparición de las nuevas tecnologías de la información y la comunicación.1

El término calidad de vida es un concepto amplio (López Trigal y Benito del Pozo, 1999) y suele estar abierto o sujeto a múltiples interpretaciones. Es por ello un concepto vivo y dinámico que con la llegada de la Sociedad de la Información ve enriquecido, en mayor medida, su ya de por sí extenso contenido. La implantación de las nuevas tecnologías de la información y la comunicación ha adquirido paulatinamente un papel protagonista en la sociedad actual, creando, de esta forma, una nueva dimensión de análisis en calidad de vida. La impronta del efecto de las nuevas tecnologías en la sociedad va en aumento y en las próximas décadas podrían llegar a ser valoradas como una necesidad básica y de carácter universal en el desarrollo vital del hombrez. Aludiendo a la complejidad de la materia, resulta muy conveniente el análisis multidisciplinar3, con interpretaciones derivadas de la geografía, la economía, la sociología y la filosofía.

\section{2.- LA GEOGRAFÍA DEL BIENESTAR}

La geografía humana de los años sesenta se caracterizaba, especialmente, por el uso de las herramientas cuantitativas. En este contexto, dominado por los métodos empíricos y las técnicas estadísticas, surgió en ciertos geógrafos la preocupación por los temas sociales, destacando inicialmente en este sentido los proyectos de Bunge (1971) y Harvey (1973) en áreas urbanas deprimidas de los Estados Unidos y Canadá.4 Éste y otros ante cedentes condicionaron la llegada en los años setenta de una segunda

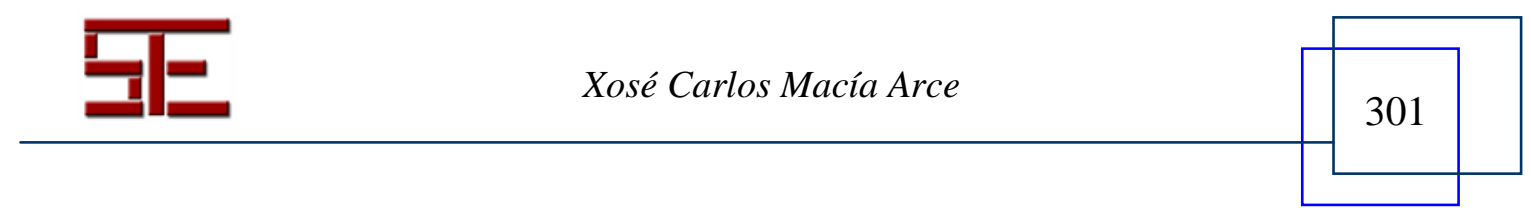




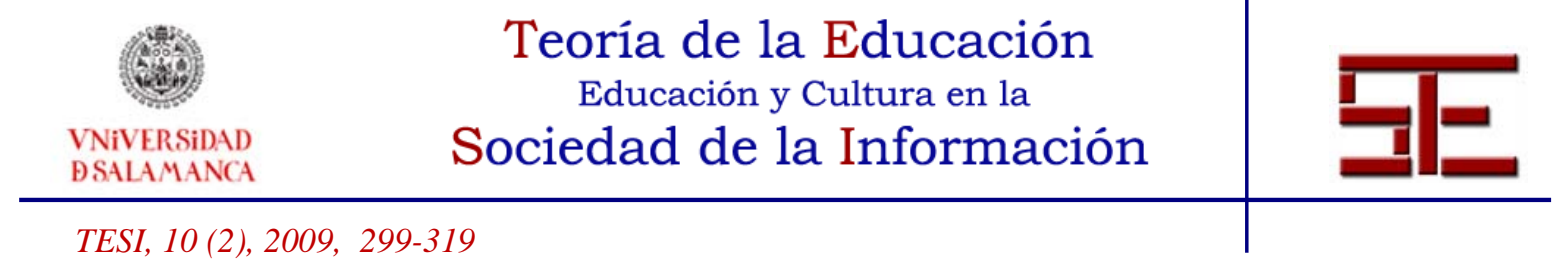

revolución en la geografía humana, interesada por las cuestiones sociales de urgencia que no encontraban su pleno desarrollo en el marco de la geografía cuantitativa, tales como la pobreza, la desigualdad, la injusticia, el hambres o los procesos de gentrificación y degradación en las ciudades. Harvey (2007), por ejemplo, denuncia la proliferación de áreas residenciales periurbanas y el abandono simultáneo de miles de viviendas en el centro de las ciudades del primer mundo. "La revolución cuantitativa y sus consecuencias contribuyeron al rigor esencial que hay que aplicar para analizar con dureza cualquier contexto de interés público. La revolución social dirigió de nuevo el interés hacia los problemas humanos reales. Si se quieren reunir las diversas corrientes de dos décadas de desarrollo de la geografía humana y constituir una ciencia social realmente al servicio de nuestros días y de nuestra época es preciso recurrir a un tema integrador. El concepto de bienestar social proporciona precisamente este tema" (Smith, 1980, pp. 28). La valoración de este bienestar social incluirá, según David Smith, todas las satisfacciones que obtiene el ser humano y su relación con la distribución dentro de la sociedad.

David Smith entiende la geografía del bienestar como una recuperación de la geografía regional, abandonada previamente en la etapa cuantitativa. La geografía regional se convierte en esta nueva etapa en un análisis de quién consigue qué y dónde en el marco de un territorio concreto. Según este autor, la contribución del geógrafo debe pasar por entender que la localización en el espacio es un factor de primera índole en las posibilidades vitales de una persona. Este aspecto revela la identificación del autor con posturas que entroncan con el relativismo cultural. Según David Smith, "pueblos diferentes ocupan territorios diferentes, y diferentes territorios atraen o rechazan fuentes diferentes de bienestar o de malestar humano" (Smith, 1980, pp. 40).6 De esta forma, el posicionamiento de un individuo o de un grupo de individuos con respecto a sus necesidades, prioridades y satisfacciones puede variar espacial e históricamente. Sus teorías hacen hincapié en el relativismo cultural, pero no hay que olvidar que su obra data de los años setenta y ochenta, una etapa previa a la explosión de la III Revolución Tecnológica y la consecuente expansión de la información y el conocimiento. Actualmente, la entrada masiva de información, ideas e incluso publicidad a través de Internet ha desembocado en una sociedad cada vez más globalizada que universaliza las necesidades y los deseos humanos, lo que rompe en cierta medida con el relativismo cultural. A través de Internet el hombre puede conocer otras realidades culturales, sociales y económicas que se producen a miles de kilómetros de distancia. La posibilidad de observar otras culturas o hábitos de vida a través de Internet provoca en el hombre nuevas necesidades o deseos que con anterioridad no necesitaba satisfacer.

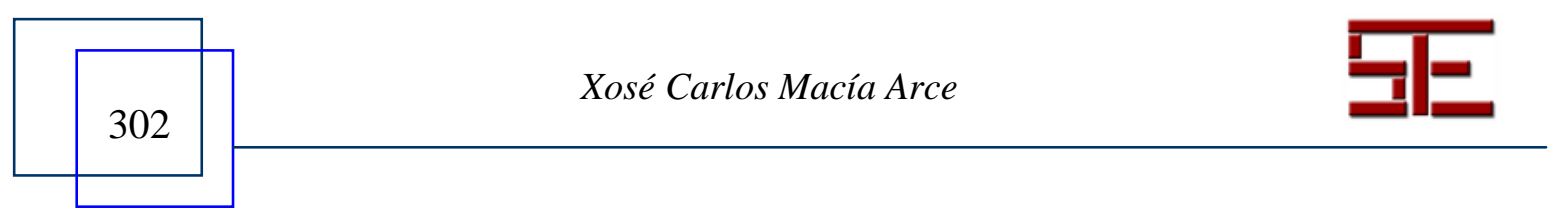




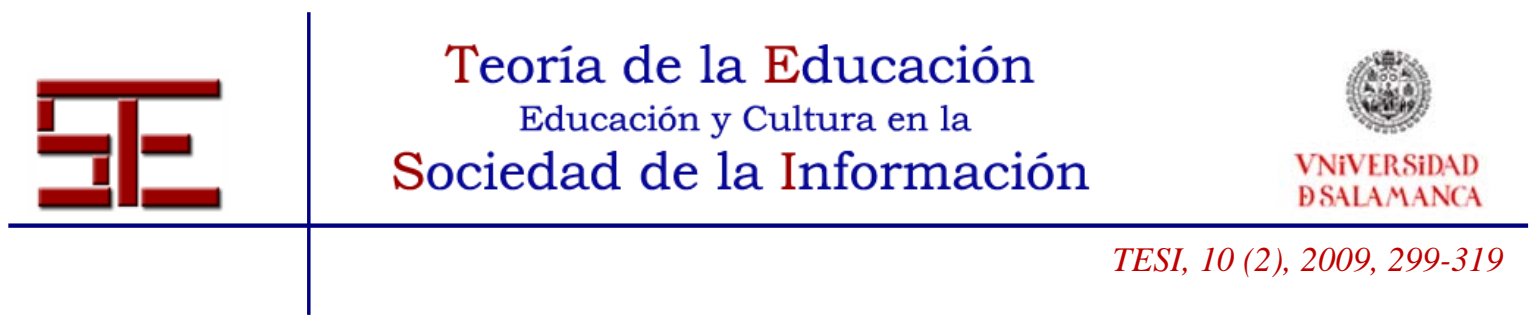

David Smith introduce aspectos éticos al recordar que la satisfacción materialista se presenta como incompleta. Asevera que en el ser humano no todo consiste en recibir, sino que en muchas ocasiones resulta más satisfactorio dar que percibir. Los problemas surgen cuando el ser humano se siente insatisfecho, situación que generalmente se identifica con espacios problemáticos, y que en las grandes ciudades se traducen en barrios multiétnicos caracterizados por una menor calidad de vida. Una meta importante en la política urbana es organizar la heterogeneidad, fomentar la comunicación entre personas de distintas nacionalidades, acortar las diferencias sociales y actuar en términos de una mayor solidaridad (Touraine, 1998). En este contexto, la planificación espacial se convierte, según David Smith, en la geografía aplicada del bienestar social. Una planificación correcta debe identificar el problema, presentar un diagnóstico, elaborar un plan y finalmente valorar los efectos. Cualquier plan urbano o regional tiene la capacidad de equilibrar las satisfacciones del colectivo, sin embargo, como denuncia David Smith, es muy poco frecuente planificar en función del bienestar social.

Las aportaciones de David Smith introducen la geografía como ciencia al servicio de la sociedad, integrándose en un ambiente multidisciplinar y huyendo de la vieja geografía descriptiva. El servicio a la sociedad entronca con la revolución social que propone la geografía como una materia enfocada a la búsqueda de soluciones concretas. La Globalización está provocando cambios económicos y sociales muy importantes que repercuten sobre el territorio. En este sentido, puede resultar muy oportuna y eficaz la conjugación de la geografía cuantitativa con la geografía social como herramienta de ayuda en la planificación urbano-regional.

\section{3.- CONSIDERACIONES SOCIOLÓGICAS EN CALIDAD DE VIDA}

En España, la sociología actual coincide con la ciencia económica en la dificultad de definir categóricamente el concepto calidad de vida. En este sentido, el trabajo de Alguacil Gómez (2000) constata la imposibilidad de dar una definición cerrada de calidad de vida, apuntando que en todo caso se podrían establecer pseudo definiciones. Por otra parte, la pretensión de este sociólogo no radica en conceptualizar, sino en mostrar las bases que puedan dar una aproximación de su contenido. No obstante, calidad de vida es un concepto muy amplio para ser limitado con exactitud y la visión práctica debe estar orientada a descubrir los indicadores que permiten medirla con mayor fiabilidad.

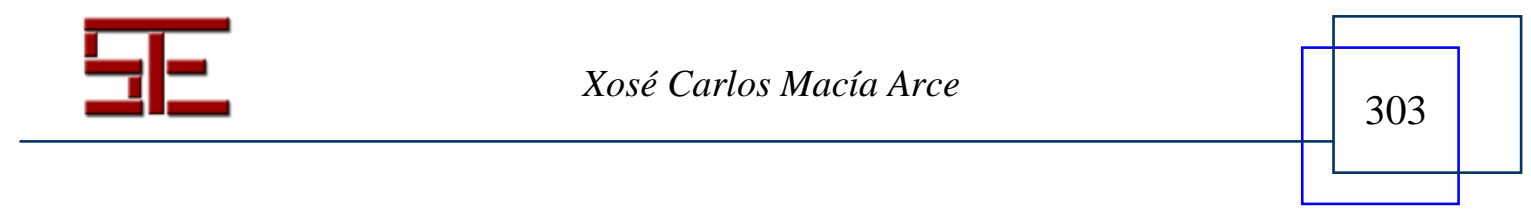




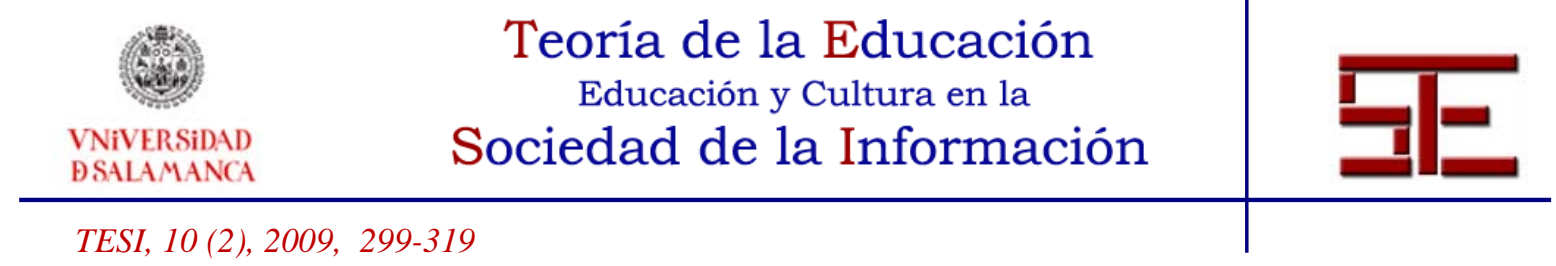

Alguacil Gómez considera que el hombre aspira a ser, tener y hacer, tres acciones que se relacionan con las necesidades y con la capacidad de satisfacer las mismas a través de una serie de instrumentos. Las necesidades varían entre los países occidentales y el resto pasando por varias escalas, es decir, existe una complicidad entre la necesidad y el desarrollo económico. Esta afirmación implica introducir las variables espacio y tiempo con objeto de confirmar un efecto de relativismo cultural. Esta conclusión del sociólogo Alguacil Gómez, recogida también por David Smith, coincide con las opiniones de un buen número de investigadores.7 Tal vez, la evolución histórica y las diferencias interterritoriales propician distintos grados de conocimiento, y son precisamente las diferencias culturales las que engendran crecimientos y desarrollos desiguales. La historia de la humanidad está marcada por la demanda de necesidades en consonancia con este conocimiento y con la capacidad para llegar a ser, tener y/o hacer algo. Por otra parte, es muy importante apreciar como con la Globalización y la llegada de la III Revolución Tecnológica, la sociedad tiene acceso a la información, expandiendo sus deseos y necesidades hacia determinados productos y calidades de vida desconocidos con anterioridad. La entrada de Internet en las comunicaciones permite a todas las sociedades e individuos apreciar las posibilidades de optar a una mayor calidad de vida. La información se internacionaliza y surgen nuevas necesidades en espacios que anteriormente desconocían la existencia de determinados bienes o situaciones de bienestar. Esta internacionalización de la información rompe en buena parte con los argumentos del relativismo cultural y su relación con la demanda de satisfacciones por parte de sociedades locales concretas, aunque se mantiene porque en la Sociedad de la Información existe un porcentaje muy elevado de población "desenganchada 0 desconectada”, al margen del uso de las nuevas tecnologías.

Alguacil Gómez argumenta que en principio las necesidades se presentan por urgencias vitales en la condición del hombre, marco en el que se inscriben las relacionadas con la salud y la seguridad, las fisiológicas, las relaciones y los derechos sociales, pero también pueden surgir a partir de deseos esporádicos alentados por el Estado y el mercado. El capitalismo de consumo puede crear necesidades alineadas o falsas necesidades. Para García Ballesteros (1998) el proceso de Globalización económica, social y cultural que afecta a la sociedad actual, desarrolla el consumo de masas que se entiende como el deseo de satisfacer necesidades que antes eran consideradas como secundarias. Los satisfactores, presentes en objetos, actividades, relaciones, estructuras o prácticas, son los instrumentos materiales y no materiales que permiten satisfacer nuestras necesidades. Los satisfactores pueden obtenerse directamente del medio natural, por ejemplo a través de la recolección, o bien, mediante procesos de transformación en respuesta a las posibilidades que ofrece la tecnología. También

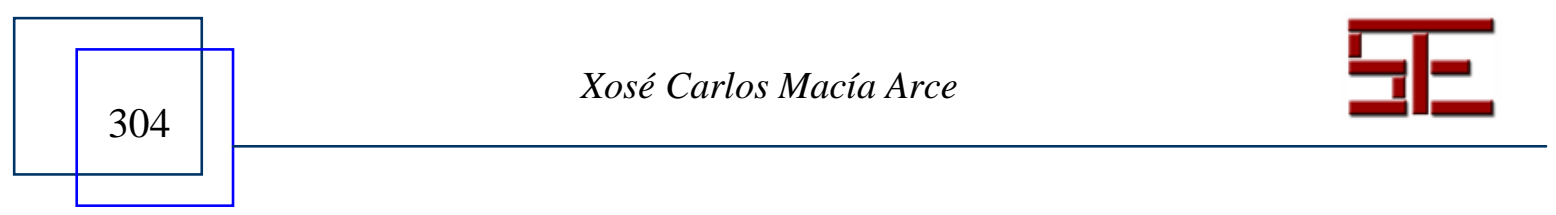




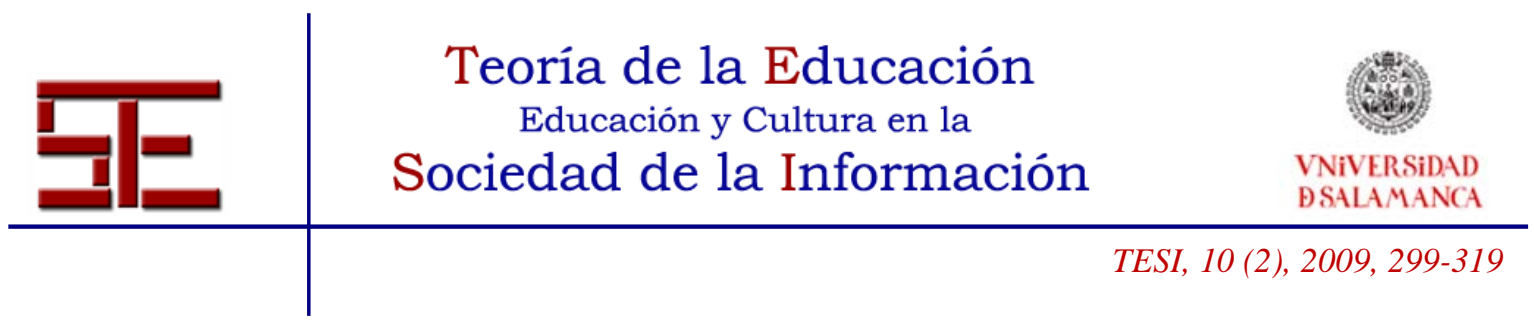

pueden conformarse a través de sistemas de organizaciones y relaciones sociales que permiten alcanzar múltiples necesidades. Alguacil Gómez considera importante que el hombre sea consciente de que los satisfactores no pueden constituir elementos destructivos del equilibrio ecológico, una idea muy acertada que expone el riesgo que supone en calidad de vida el uso inapropiado de la naturaleza. Satisfacer las necesidades en equilibrio con el medio ambiente supone elevar el bienestar de una comunidad hacia una verdadera calidad de vida.

Algunos investigadores constatan que con la llegada de la III Revolución Tecnológica se están remodelando de forma clara los espacios rurales y urbanos. Los geógrafos estudian las ciudades abiertas como superación de la masificación ciudadana de la época industrial, analizando las implicaciones de la desconcentración sobre los espacios rurales circundantes. Cada vez es mayor el número de personas que prefieren instalarse en el campo, atraídas por las nuevas oportunidades de trabajo, la adquisición de viviendas de una mayor calidad y menor precio, la seguridad ante el aumento de la criminalidad urbana, un ambiente menos contaminado, etc., (Ferrás Sexto, 1999). Esta consecución de las necesidades respetando los valores ecológicos, supone, según Alguacil Gómez, entrar en una dimensión ética en la que sólo queda por incluir el mantenimiento de la plena autonomía del individuo, tanto para actuar como para pensar, sin ningún tipo de condicionamientos políticos. La descentralización del poder público en unidades de gestión y administración menores, como gobiernos regionales y locales, permiten al ciudadano aprovechar óptimamente los recursos exógenos y endógenos, contribuyendo al equilibrio necesidades-satisfactores. Sin duda, este aspecto revela la importancia de la democracia político-administrativa en la calidad de vida de las personas. En este sentido, Internet representa una poderosa herramienta capaz de introducir nuevos comportamientos o hábitos en la sociedad. Una sociedad civil bien organizada y tomando Internet como medio de comunicación no mediático, puede dar lugar a una mayor democracia, lo que se conocería como la cyberdemocracia (Gés, 1997). Con estas premisas, Alguacil Gómez (2000, pp. 107) culmina definiendo la calidad de vida como "un grado óptimo de felicidad (espiritualidad, subjetividad, y autonomía de la ética) y bienestar (materialidad, objetividad, y autonomía de la economía)”.

Por otra parte, Setién Santamarías (1990) definió calidad de vida como el grado en que una sociedad satisface las necesidades de sus miembros, tomando en consideración los aspectos objetivos y el sentimiento de satisfacción que poseen los miembros de esa sociedad. Su enfoque adopta un estudio multidimensional, englobando múltiples

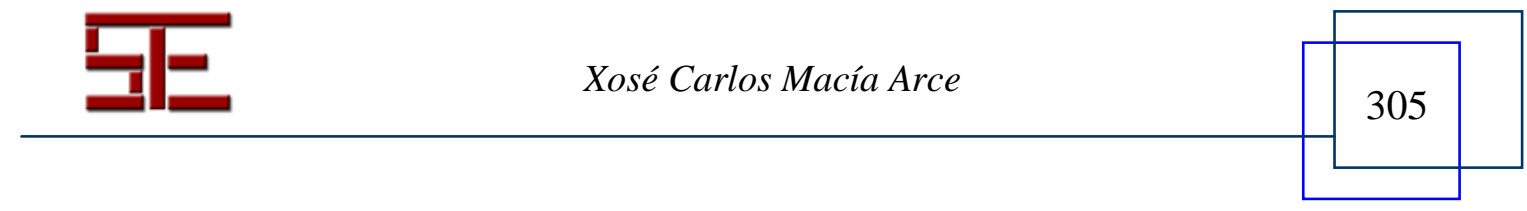




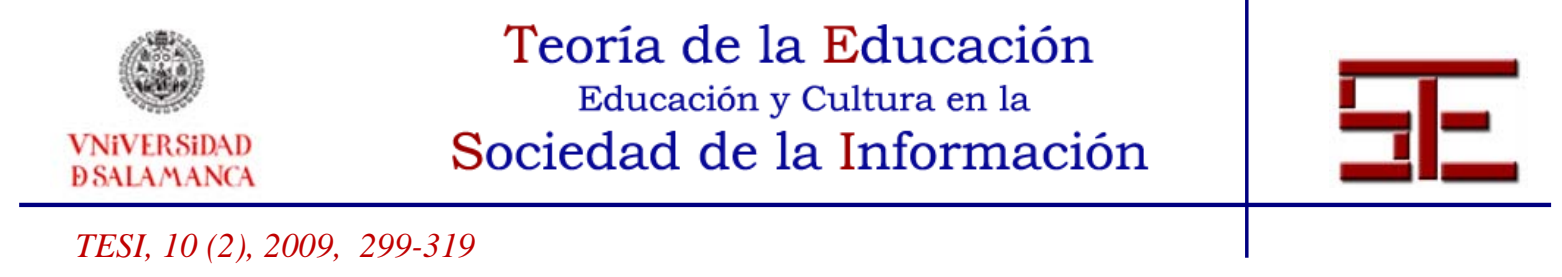

aspectos que hacen referencia al desarrollo de la vida humana. Entre los aspectos seleccionados incluye e iguala en rango de importancia, como refleja la definición, los indicadores y las variables de tipo perceptivo. La estructura final diferencia dimensiones y áreas que analizan la salud, la vivienda, el trabajo, el ocio, la renta, la familia, la seguridad, el entorno físico-social, la religión, la educación y la política. Su contribución hace especial énfasis en los indicadores de tipo perceptivo porque es importante contentar a la sociedad pero también lo es conocer su grado de satisfacción. Las autoridades públicas gestionan y toman decisiones que repercuten de forma directa en el mayor o menor bienestar del colectivo. Una vía propicia para alcanzar el éxito debe pasar necesariamente por conocer las impresiones de la ciudadanía.

\section{4.- ECONOMÍA Y CUANTIFICACIÓN EN CALIDAD DE VIDA}

El Comité de las Naciones Unidas expresó en cierta ocasión que las condiciones de vida presentes en un momento dado de la colectividad son las que determinan el nivel de vida. Jan Drewnowski (1965) "cuantificaba el estado o grado de bienestar tal como existe y puede ser medido en un momento dado". Estas afirmaciones denotan dos circunstancias muy importantes. Por un lado se hace referencia a una visión temporal; el hecho, en este caso el nivel de bienestar, se inscribe en un tiempo concreto. Por otra parte, se proponen unas pautas en el sistema de medición; el nivel de bienestar se calcula sobre la base de unos indicadores caracterizados por la posibilidad de ser cuantificados.

Pena Trapero (1977) comparte las opiniones mencionadas y las reafirma y amplia al contemplar la medición del bienestar de vida como un conjunto de situaciones objetivas. Encara el estudio desde dos perspectivas, la económica y la ofrecida por las grandes instituciones internacionales. La suma de conocimientos los traduce en tres tipos de enfoques orientados a medir la calidad de vida:

1. El punto de vista contable

2. El sistema los indicadores

3. Las funciones de utilidad

El punto de vista contable fue empleado de forma universal por los distintos países hasta los años sesenta. Se trataba de un método de medición incompleto que identificaba el nivel de vida con el nivel de consumo, dejando muchos aspectos sin valorar. La idea directriz residía en la aceptación de la analogía entre el flujo de bienes y servicios con el flujo del haber monetario, pagado para la adquisición de dichos bienes y

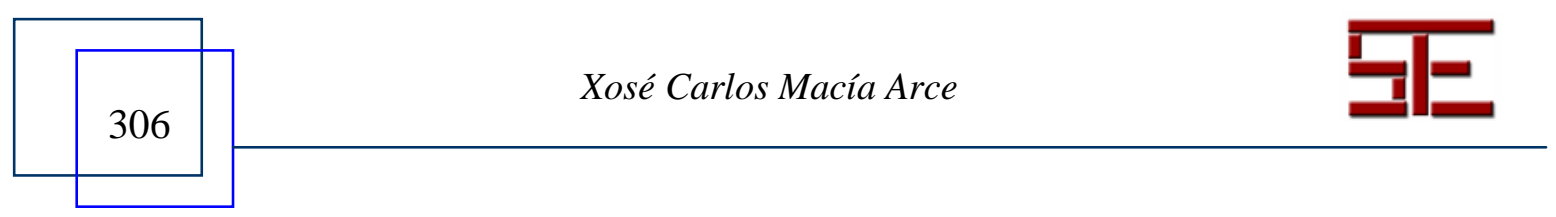




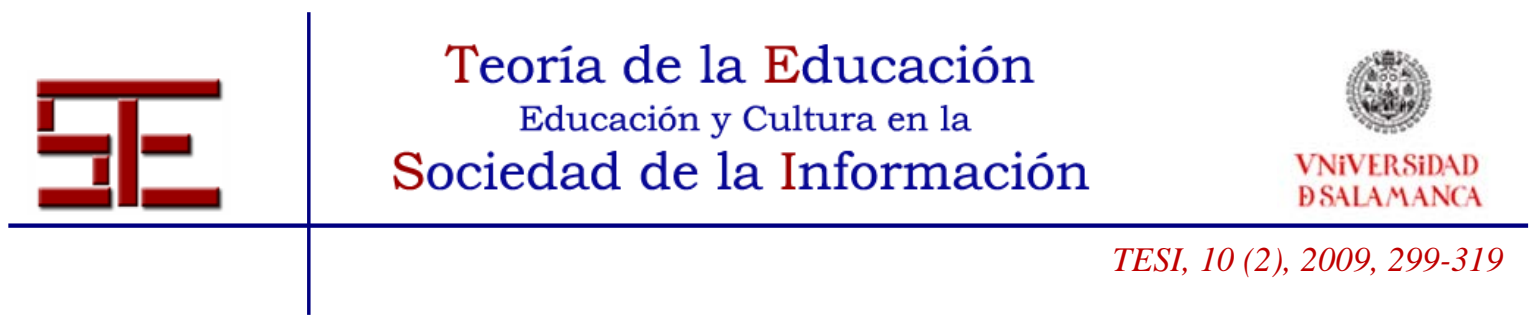

servicios. Los indicadores se centraban en las rentas, el consumo per cápita y el análisis de los presupuestos familiares; un razonamiento muy pobre que dejaba muchos aspectos sin medir, como por ejemplo el ocio.

El sistema de indicadores engloba todos los aspectos relacionados con la sociedad, integrando los componentes de salud, consumo de alimentos y nutrición, educación, empleo y condiciones de trabajo, vivienda, seguridad social, vestido, recreo y libertades humanas. Estos componentes requieren elaborar una lista detallada de todas las preocupaciones, sub preocupaciones, y en algún caso sub sub preocupaciones.

En la selección de indicadores, Pena Trapero estima oportuno incluir la opinión de Clause Moser9, director de la Facultad Estadística Central del Reino Unido, que en 1975 elaboró para la Organización de las Naciones Unidas el informe SESD (Sistema de Estadísticas Sociales y Demográficas). Este informe señalaba la idoneidad de que los indicadores se ajustaran a una serie de criterios convenientes:

1. Adecuación: los indicadores deben proporcionar medidas que se ajusten al aspecto de las condiciones de vida.

2. Capacidad de compendiar: el diseño debe ser apropiado con vistas a incorporar la mayor cantidad de información.

3. Coordinación: los datos deben conformar un conjunto coherente y vinculado.

4. Exactitud y capacidad de comparación: la exactitud no requiere ser extremadamente elevada pero si debe ser aceptable y sobre todo permitir la comparación.

5. Oportunidad: los datos deben estar disponibles en un plazo razonable para ser realmente útiles.

6. Viabilidad: los datos no pueden centrarse en el campo de la abstracción.10

Clause Moser tradujo la consideración de todas estas premisas en la siguiente lista de indicadores en calidad de vida:

1. Población

2. Aprendizaje y servicios de enseñanza

3. Actividades remuneradas y servicios de empleo

4. Distribución del ingreso, el consumo y la riqueza

5. Seguridad social y servicios de asistencia social

6. Salud y servicios de la salud

7. Vivienda

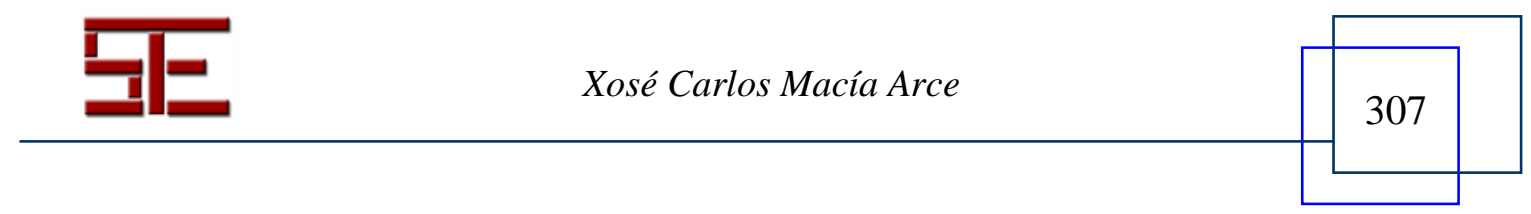




\section{\begin{tabular}{cc} 
Teoría de la Educación \\
Educación y Cultura en la \\
$\begin{array}{c}\text { VNiVERSIDAD } \\
\text { BSALAMANCA }\end{array}$ \\
\hline TESI, 10 (2), 2009, 299-319
\end{tabular}}

8. Seguridad y orden público

9. Distribución del tiempo y uso del tiempo libre

10. Estratificación y movilidad sociales

Un informe de la OCDE, institución internacional que reúne a los países más industrializados o avanzados con objeto de armonizar políticas que maximicen su crecimiento económico y el de los países no miembros, enriquece la lista de indicadores incluyendo los relacionados con la percepción, los cuales recogen las apreciaciones subjetivas de los individuos en relación con su nivel de satisfacción o bienestar. Pena Trapero conoce la existencia de los mismos pero los rechaza alegando que no son operativos por su incapacidad para ser medidos.

Por otra parte, en la medición del nivel de vida basándose en funciones de utilidad, la teoría clásica del consumidor individual se basa en la aceptación de la posibilidad de medir la utilidad según escalas ordinales, a partir de un axioma único de preferencias ordenadas. Un conjunto cualquiera de situaciones de consumo A, B, C, D, etc., se puede disponer siguiendo un orden coherente y único de preferencia ascendente. El problema se plantea al intentar constituir una escala de preferencias colectivas similar a la escala de preferencias individuales11.

John Kenneth Galbraith (1996) sin pretender conceptuar ni presentar los indicadores que definen e integran la calidad de vida, sí denunció, sin embargo, las carencias que sufre la sociedad como consecuencia de los errores políticos en la gestión pública. Al igual que otros destacados economistas norteamericanos, como Paul Samuelson,12 las teorías económicas de Galbraith entroncan con la lógica capitalista norteamericana, no obstante, critica el sistema de mercado que no protege ni a los consumidores ni al medio ambiente, y que distribuye la renta con gran desigualdad afectando a los intereses sociales. 13 Asevera que una buena sociedad será aquella que permita a cada uno de sus miembros, sin distinciones de sexo, etnia o raza, tener acceso a una vida gratificante, y en este sentido, el Estado debe ser protagonista en el auxilio hacia los más necesitados, 14 incluyendo ayudas sanitarias, subsidios de paro y una enseñanza pública eficaz. La discriminación sigue siendo algo característico de nuestras sociedades. La era de la información global es también la de la segregación local (Borja y Castells, 1997). En esta misma línea, centrada en las desigualdades sociales, Neil Smith (1984) diseñó la Teoría del Desarrollo Desigual. Para este autor, todas las escalas espaciales presentan distintos grados de desarrollo, y el capital, sobre todo en la escala urbana, está en un movimiento constante que permite explicar el desarrollo reciente de áreas deprimidas en

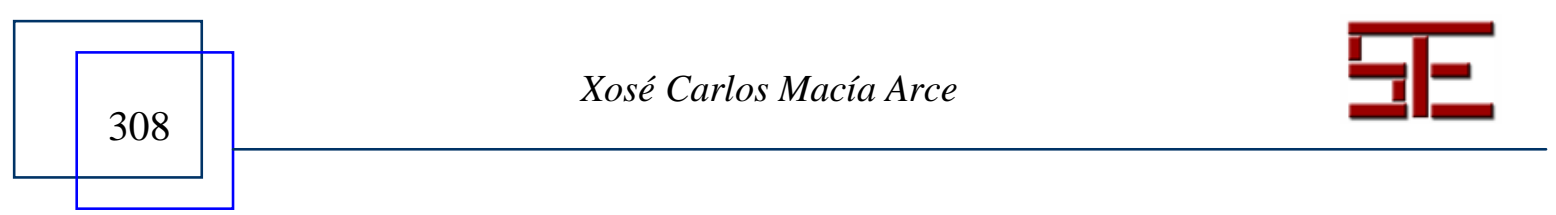




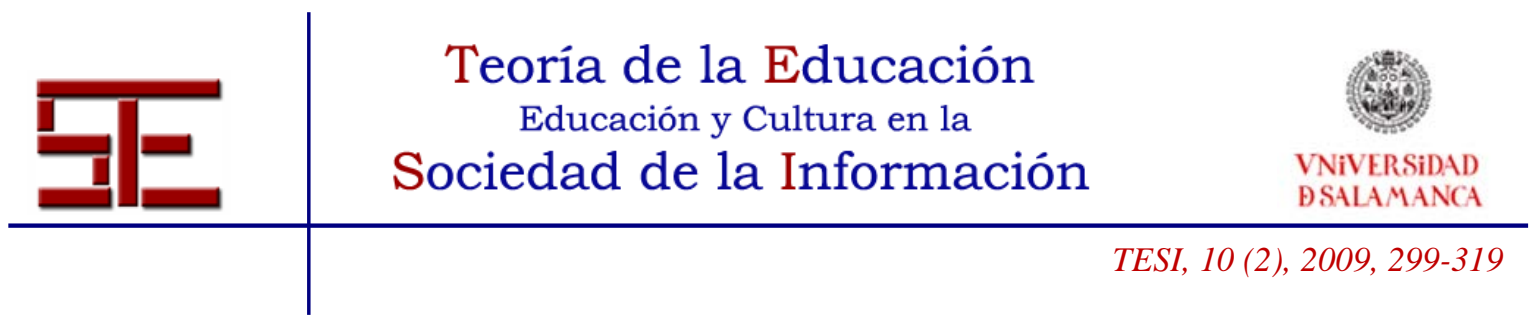

el interior de las ciudades (posibles procesos de gentrificación) y al revés (procesos de degradación urbana).

En la concepción de Kenneth Galbraith existe una diferencia muy notable en la relación que combina las aspiraciones de las personas con sus potencialidades. Los ciudadanos difieren en las capacidades físicas y mentales, y en la reciedumbre y constancia en el trabajo, y estas disparidades propician una escala muy variada de compensaciones económicas. Su frase: "De cada cual según sus capacidades, a cada cual según sus necesidades" (Galbraith, 1996, pp. 112),15 apunta que la sociedad no busca la igualdad en la distribución de la renta y choca frontalmente con el planteamiento solidario de David Smith (1980).

\section{5.- PREFERENCIAS SOCIALES Y LOS DERECHOS FUNDAMENTALES DE LAS PERSONAS}

Amartya Sen, destacado economista, alcanza su mayor reconocimiento en 1998 con el Premio Nobel en Ciencias Económicas. Sus estudios adicionales en filosofía le confieren una gran capacidad de crítica que utiliza contra los planteamientos políticos que confunden medios y fines y se olvidan de que la vida y la satisfacción de las personas deben estar por encima de la producción.16 Cada individuo posee una escala de necesidades que se supone que la sociedad ordena tomando en consideración el conjunto de todas las preferencias individuales. Estas necesidades las enfoca como funcionamientos representativos de las cosas que la persona logra hacer o ser. Algunos funcionamientos son elementales y básicos para la subsistencia del hombre, otros son complejos y difieren mucho en la elección y en la ponderación, que puede ser positiva y negativa, identificando una serie de objetos valiosos que se reflejan en una jerarquización. Es decir, cuando menciona los funcionamientos deja entrever que existen necesidades y deseos. Las primeras pueden ser imprescindibles para el desarrollo del hombre. Los deseos por el contrario pueden ser valiosos o perjudiciales, alcanzables o inalcanzables, y estas connotaciones son las que exigen la necesidad de jerarquizar en una escala de valores las mercancías y acciones que suponen la prosperidad y el bienestar social de una comunidad. Cuando los deseos del hombre están por encima de las necesidades básicas, el Estado del Bienestar y la democracia pierden su razón de ser (Viveret, 2002). Nace, entonces, la preocupación por la teoría de la elección colectiva, una materia relacionada con la economía, la ciencia política y la filosofía.17

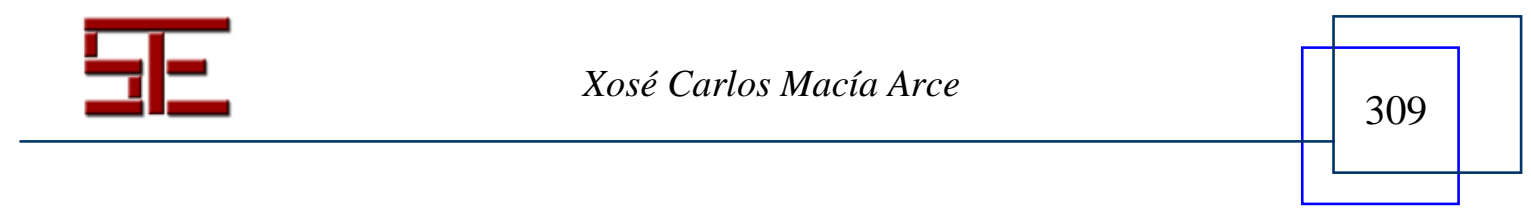




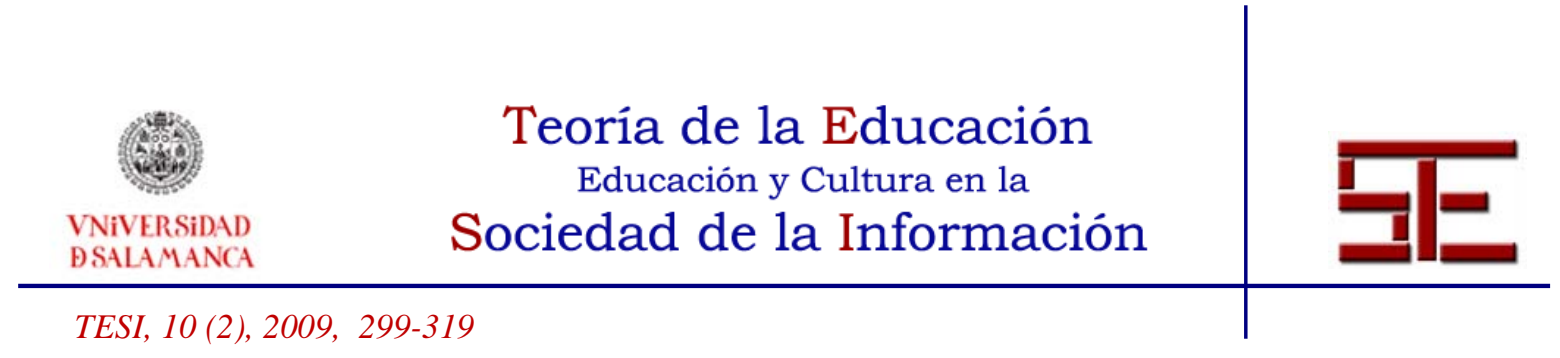

La reflexión teórica de Amartya Sen18 suele hacer referencia a dos economistas de reconocido prestigio: Vilfredo Pareto19 y John Kenneth Arrow.20 El primero empleó un criterio de valoración del bienestar muy simple, asociado a dos reglas fundamentales: a) si todos los individuos se muestran indiferentes ante dos posibles alternativas, entonces la sociedad debería ser también indiferente; b) si un individuo prefiere $\mathrm{x}$ a $\mathrm{y}$, y el resto se muestra indiferente, la sociedad también debería preferir x a y. Partiendo de estos dos supuestos, los economistas consideran el concepto de Optimalidad de Pareto cuando en un conjunto de alternativas $\mathrm{x}$, una se considera la óptima si no existe otra que la sociedad considere estrictamente mejor (Amartya Sen, 1976). Esta teoría es la base de la moderna economía del bienestar y de gran parte de los programas políticos. David Smith (1980) critica la Optimalidad de Pareto, dado que ésta contempla como mejoras los cambios que favorecen al rico sin perjudicar al pobre, es decir, acepta una teoría que aplicada al bienestar regional no admite ninguna preocupación por la equidad distributiva. Para Esping Andersen (2001), Pareto define la optimización del bienestar como una redistribución que produce una mayor eficacia sin perjudicar a nadie, pero, hay un segundo principio más ambicioso, el Principio de Justicia de Rawles, según el cual toda mejora debe ser ventajosa para la comunidad, pero, sobre todo debe ser ventajosa para los más pobres y débiles. Es decir, Esping Andersen considera necesario redefinir el concepto de derechos sociales en una línea de mayor igualdad y oportunidades para todos, opinión que mantiene Casey (2005) cuando afirma que el desarrollo del individuo tiene que estar inexorablemente unido al desarrollo de la comunidad. Amartya Sen, por su parte, puntualiza que se trata de una regla importante pero incompleta.

El economista John Kenneth Arrow (1970) influenció en gran medida el pensamiento de Amartya Sen a través de su Teorema de la Imposibilidad21, en el que analiza las preferencias de los miembros de un colectivo en una preferencia social agregada. El Teorema deduce que existen situaciones en las que no es posible determinar una ordenación racional de las preferencias de la sociedad. Kenneth Arrow (1970) explica el problema certeramente: "se enuncian ciertas propiedades que debe poseer toda función de elección social razonable. Luego se examina la posibilidad de satisfacer estas condiciones. Si tenemos suerte habrá exactamente una función de elección social que las satisfará. Si somos menos afortunados podrá haber varias funciones de elección social que satisfagan las condiciones o los axiomas. Por último, será el colmo de la mala suerte que no exista ninguna función que satisfaga las condiciones deseadas” (Amartya Sen, 1995, pp.185). El teorema se basa en cuatro principios imprescindibles para convertir las preferencias individuales en una preferencia social:

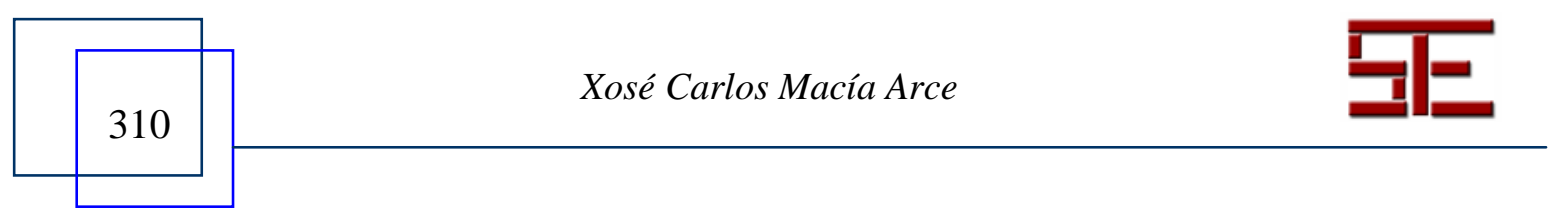




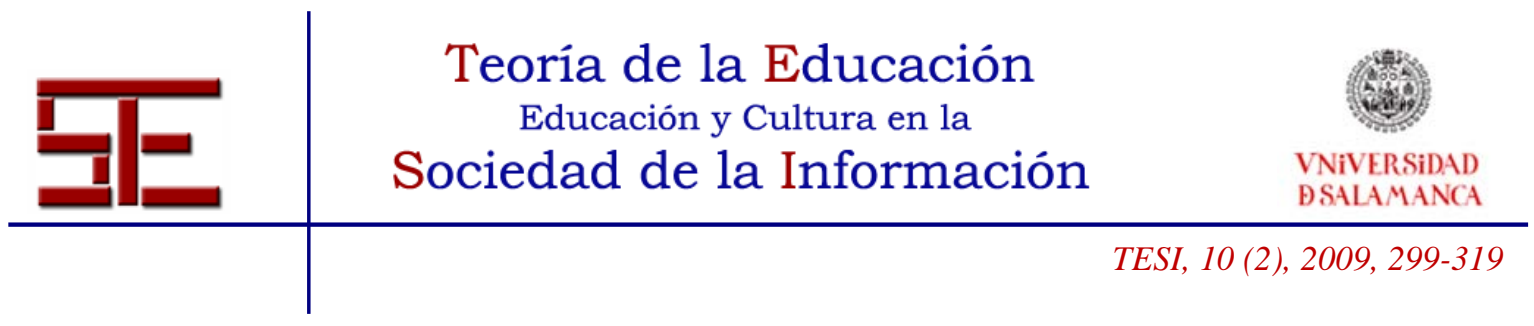

1. El dominio irrestricto. Exige que se incluyan todas las preferencias individuales posibles.

2. El principio de Optimalidad de Pareto, anteriormente explicado.

3. La independencia de las opciones irrelevantes. No deben existir alternativas sin trascendencia que influyan en la decisión.

4. La ausencia de dictadura. Un individuo no puede anteponer su decisión al grueso de la colectividad.

El Teorema de la Imposibilidad puede entenderse como un teorema completo y certero, pero Kenneth Arrow (1970) afirma que no existe ninguna función de bienestar social capaz de satisfacer las cuatro condiciones (Amartya Sen, 1995).

Amartya Sen distingue, también, dos conceptos muy importantes: las realizaciones y las capacidades. Las primeras hacen referencia a las distintas condiciones de vida que alcanzan o pueden alcanzar las personas; las segundas están relacionadas con el potencial, es decir, las habilidades de las mismas para lograr algo. La complicación surge cuando la gente valora heterogéneamente las cosas que puede hacer o ser, un hecho que se agrava con la disparidad de capacidades que varían entre situaciones tan elementales como estar bien alimentado, hasta llegar a otras enormemente complejas, como alcanzar la participación social. La calidad de vida la concibe y la evalúa en términos de actividades bien valoradas y en la capacidad de alcanzarlas, circunstancias que miden el éxito de la persona. Critica los planteamientos que miden los objetos de valor en función de las mercancías, porque como bien señala, el requerimiento de alimentos para la capacidad de estar bien alimentado puede variar entre los individuos (sexo, edad, metabolismo...) y entre las distintas sociedades (ingresos, condiciones climáticas...), y lo mismo sucede con los campos de la vivienda, la educación y la salud (Amartya Sen, 1996). Esta aseveración reitera el relativismo cultural precisado por Alguacil Gómez (2000), Dehesa Romero (2000), Méndez (1997), Castells (1995) y Smith (1980). Además, en base a la diversidad que presentan las necesidades y los deseos en función de la edad y el sexo de las personas, exige la realización de análisis demográficos para conocer con mayor precisión las necesidades reales de una comunidad local.

En la década de los ochenta Len Doyal e Ian Gough (1994) colaboraron en una investigación sobre bienestar social y calidad de vida en las personas. En su obra común mantienen que las necesidades humanas son históricas, producto de una construcción social progresiva, pero puntualizan que estas necesidades son universales y que todos

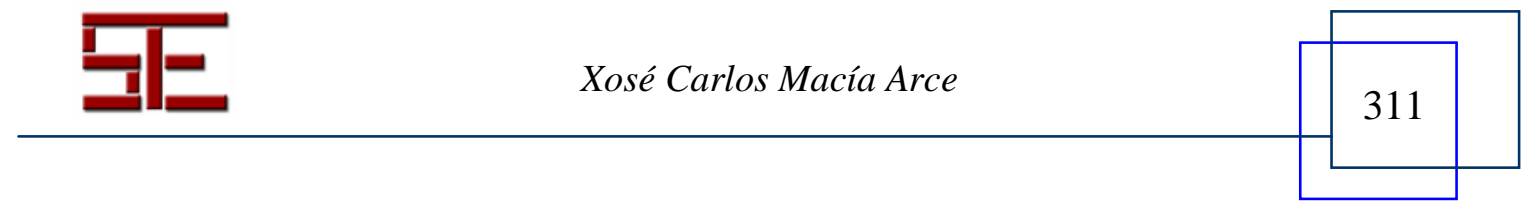




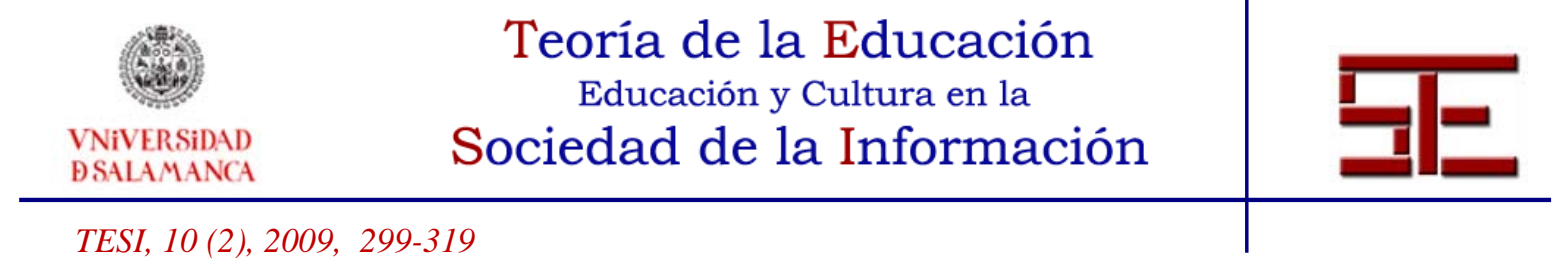

los individuos tienen derecho a satisfacer las mismas. Existen necesidades básicas, como la supervivencia física o la autonomía personal, que no dependen de las preferencias subjetivas de cada individuo ni de los planificadores políticos, y que en ningún caso pueden variar como consecuencia de las diferencias espaciales. Esta teoría supone una revolución que rompe con el relativismo cultural de otros estudiosos de la materia. Consideran que no admitir este supuesto significa ocultar las situaciones de privación de necesidades básicas tras argumentaciones que alegan diferencias culturales $\mathrm{y}$, por tanto, justificar y promover las diferencias entre naciones desarrolladas $\mathrm{y}$ subdesarrolladas22. Es responsabilidad y debe ser el Estado quien organice la política de bienestar con objeto de satisfacer las necesidades humanas. El problema radica en averiguar cuáles son esas necesidades y cuál es el modo apropiado de satisfacerlas. La solución óptima apunta a la participación y decisión del hombre en estas cuestiones, por lo que el sistema político democrático se convierte en un instrumento fundamental,23 opinión compartida por Amartya Sen (2000) que concibe la libertad como el rompimiento de las ataduras que posibilita al individuo ejercer su voluntad a partir de un juicio racional.

\section{6.- SUMARIO CRÍTICO. CALIDAD DE VIDA Y EXCLUSIÓN SOCIOTERRITORIAL EN LA SOCIEDAD DE LA INFORMACIÓN}

Así pues, se podría afirmar que el término calidad de vida abarca un dominio temático muy complejo. Todos los estudios realizados hasta la fecha en esta materia, algunos muy certeros, aluden a la dificultad de determinar con precisión el concepto, el contenido y la medición. La calidad de vida incluye todos los aspectos que cubren y satisfacen las necesidades y deseos del hombre y, por tanto, la llegada de la III Revolución Tecnológica aumenta muy significativamente todas las variables relacionadas con la comunicación, la información y el conocimiento. En suma, el concepto calidad de vida podría entenderse como el grado de satisfacción que alcanza una sociedad en las áreas relacionadas con la subsistencia, la salud, la protección, la vivienda, la información, el conocimiento, la comunicación, el trabajo, la renta, la familia, la política, la calidad ambiental, el ocio y la cultura, adquiriendo como indicadores y variables los parámetros tangibles y los parámetros intangibles que entroncan con la percepción de la ciudadanía. La gran oportunidad que representa la Sociedad de la Información es que casi todas las dimensiones, áreas y variables en calidad de vida se relacionan o se pueden relacionar de alguna manera con las nuevas tecnologías de la información y la comunicación. El desarrollo de nuevas redes, como Internet, tiene una gran repercusión económica, pero, también social y cultural (Jospin, 1997).

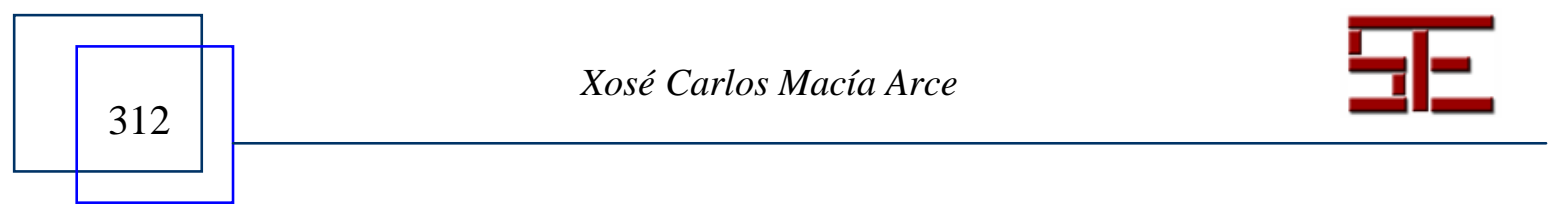




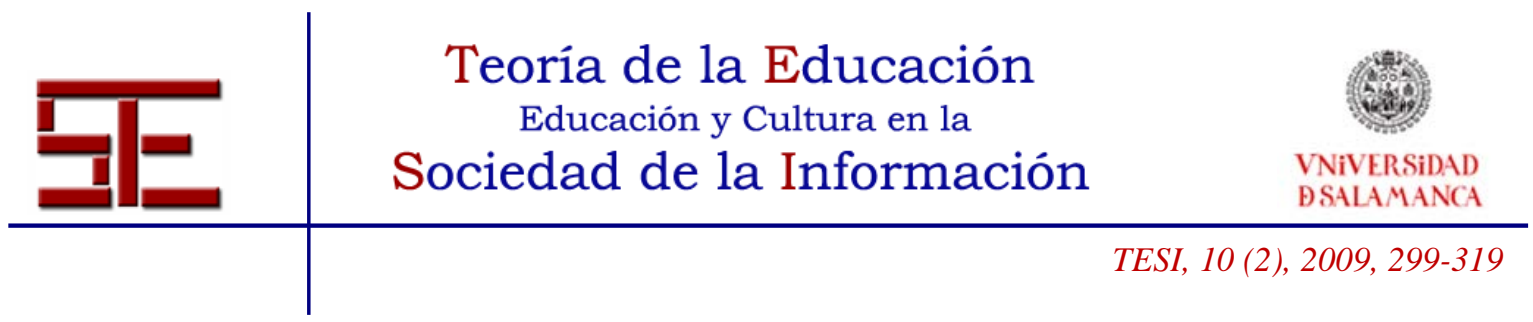

Por tanto, la distribución discriminatoria e injusta de las nuevas tecnologías sobre el territorio podría incidir negativamente en la calidad de vida de muchas comunidades, aumentando las desigualdades y los desequilibrios socioespaciales. La nueva sociedad mal dirigida podría acentuar el mapa de ganadores y perdedores, con sociedades “enganchadas a la red" y "sociedades desenganchadas o apagadas", provocando una gran fractura social y territorial.

En los últimos años, los distintos grados de penetración de las nuevas tecnologías de la información y la comunicación sobre el territorio están provocando y acentuando las diferencias sociales y los desequilibrios económicos entre diferentes espacios y comunidades. Esta coyuntura implica un distanciamiento, todavía mayor, entre las naciones y grupos sociales más aventajados y, por otra parte, los espacios y colectivos humanos menos favorecidos por el crecimiento económico (Dehesa Romero, 2000b). La llegada de las nuevas tecnologías de la información y la comunicación ha supuesto en múltiples ocasiones el alejamiento social y económico de infinidad de comunidades locales que permanecen apagadas, desenganchadas o desconectadas de las ventajas que ofrecen las nuevas tecnologías de la Sociedad de la Información, de tal forma que no son capaces de mejorar la calidad de vida de sus ciudadanos. "La velocidad de la difusión tecnológica es selectiva, tanto social como funcionalmente” (Castells, 2000, pp. 64). Las personas, empresas y países que no sepan adaptarse al cambio tecnológico, permanecerán marginadas y con menores posibilidades de desarrollo (Dehesa Romero, 2000b). Estas diferencias socio espaciales de accesibilidad técnica y de uso y disfrute de las nuevas tecnologías conforman lo que algunos científicos denominan la Brecha Digital (Ferrás Sexto et al, 2004, 2004b) o la Divisoria Digital (Castells, 2000). El nuevo mundo de las comunicaciones electrónicas incluirá ganadores y perdedores (Dehesa Romero, 2000b; Cairncross, 1998).

\section{BIBLIOGRAFÍA}

ALGUACIL GÓMEZ, Julio. Calidad de vida y praxis urbana. Nuevas iniciativas de gestión ciudadana en la periferia social de Madrid. Madrid: Siglo XXI de España Editores, 2000.

ARROW, John Kenneth. Social choice and individual values. New Haven: Yale University, 1970.

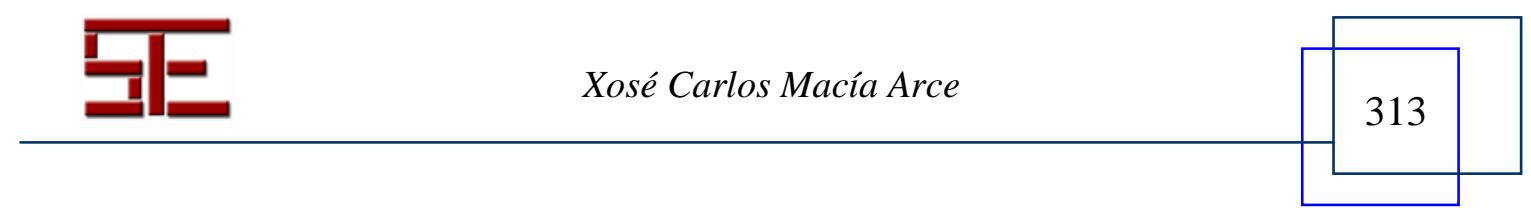




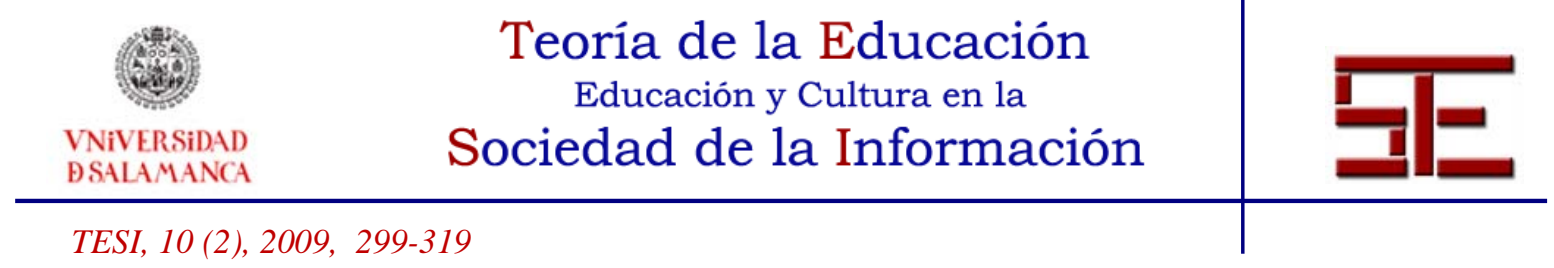

BILBAO, AYUNTAMIENTO DE. Bilbao Metrópoli 30. Lista de indicadores. [en línea]. Bilbao: 1999 [ref. de 10 de abril 2003]. Disponible en web: http://www.terrassa. org/laciutat/xifres/estudis/perfildelaciutat/informese.html

BORJA, Jordi; CASTELLS, Manuel. “La ciudad multicultural”. La Factoría [en línea]. 1997, no. 2 [ref. de 27 marzo 2003]. Disponible en Internet http://www.lafactoriaweb.com/articulos/borjcas2.htm

BUNGE, Willian. Fitzgerald: The Geography of a Revolution. Cambridge: Sherman, 1971.

CAIRNCROSS, Frances. The death of distance 2.0. How the communications revolution will change our lives. Londres: Texere, 2001.

CASEY, Ciarán. "Broadband and Rural Development: Opportunities and Challenges for Social Exclusion” en Irish LEADER Support Unit, 2005. Disponible en: http://www.ilsu .ie/documents/ILSU\%20pubs/Broadband-Ciaran.pdf

CASTELLS, Manuel. La era de la información: economía, sociedad y cultura. La sociedad red. $2^{a}$ ed. Madrid: Alianza Editorial, 2000.

CASTELLS, Manuel. La ciudad informacional: tecnologías de la información, reestructuración económica y el proceso urbano-regional. Madrid: Alianza Editorial, 1995.

COMISIÓN EUROPEA, POLÍTICA REGIONAL. The Urban Audit: Towards the Benchmarking of Quality of Life in 58 European Cities, Vol. I, II. [en línea].

Luxembourg: European Communities, 2000 [ref. de 14 de noviembre 2002]. Disponible en Web: http://europa.eu.int/comm/regional _policy/urban2/urban/audit/src/publics.htm

DEHESA ROMERO, Guillermo de la. Comprender la globalización, Madrid: Alianza, 2000.

DEHESA ROMERO, Guillermo de la. “¿Consolidará Galicia a súa converxencia real no século XXI?” en Revista Galega de Economía, vol. 9, nº 1, 2000b, pp. 7-24.

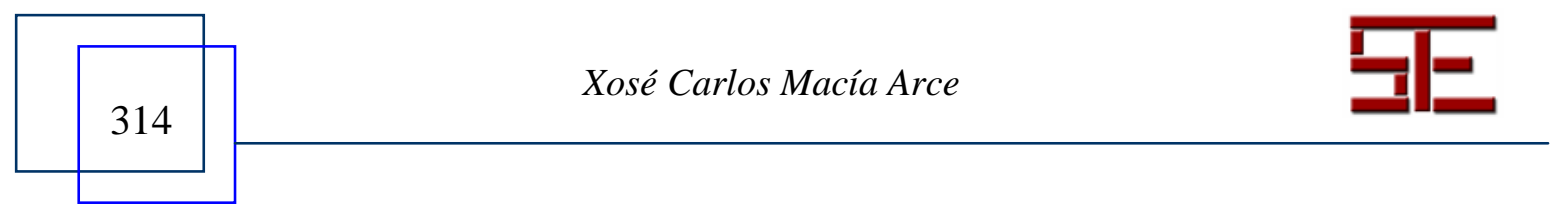




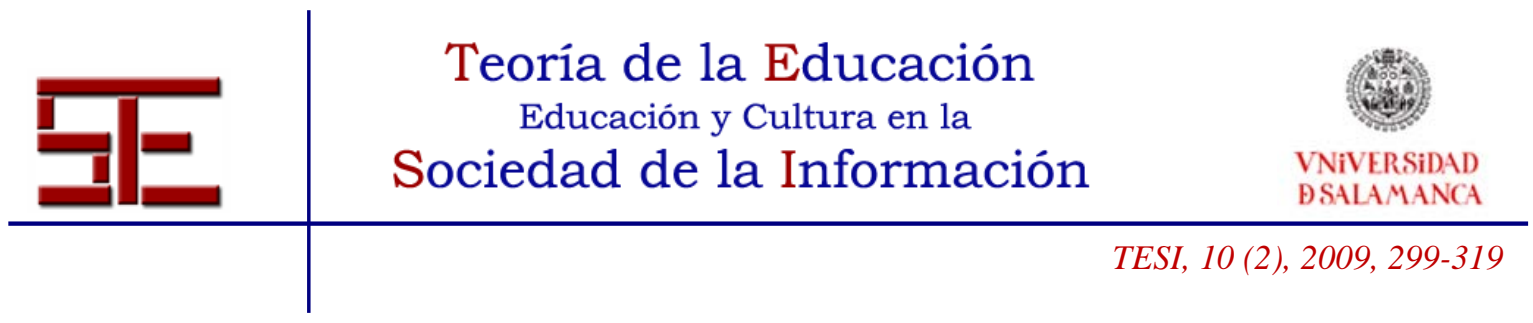

DOYAL, Len; GOUGH, Ian. Teoría de las necesidades humanas. Barcelona: Tesys, 1994.

DREWNOWSKI, Jan. El nivel del Índice de Vida. Ginebra: Instituto de las Naciones Unidas para la Investigación Social y el Desarrollo, 1965.

ESPING-ANDERSEN, Gösta. “Un Estado de Bienestar europeo para el siglo XXI”. La Factoría [en línea]. 2001, no. 13 [ref. de 27 marzo 2003]. Disponible en Internet: http://www.lafactoriaweb.com/articulos/gosta13.htm

ESTRUCH MANJÓN, Alejandro. "Estado del Bienestar, desigualdad y redistribución: algunos datos e ideas en el cambio de siglo" [en línea]. [s.n.]. c.a. 2002. http://www.ub.es/graap/WP0801_Estruch.pdf [consulta: 10 septiembre 2002].

FERRÁS SEXTO, Carlos; GARCÍA VÁZQUEZ, Yolanda; ARMAS QUINTÁ, Francisco Xosé; MACÍA ARCE, Xosé Carlos. "Metodoloxía de intervención fronte á fenda dixital. A experiencia de www.infobrion.com." en I Xornadas SINDUR: Internet $i$ Educación, Universidade de Santiago de Compostela, 2004, pp. 33-70.

FERRÁS SEXTO, Carlos; ARMAS QUINTÁ, Francisco Xosé; GARCÍA VÁZQUEZ, Yolanda; MACÍA ARCE, Xosé Carlos. "Metodología de intervención para vencer la brecha digital. La experiencia de www.infobrion.com" En: Actas VI Coloquio Internacional Geocrítica: El impacto social y espacial de las nuevas tecnologías de la información y de la comunicación, Scripta Nova [en línea]. 2004b, vol. VII. Disponible en Internet: http://www.ub.es/geocrit/menu.htm

FERRÁS SEXTO, Carlos. "La Ciudad Dispersa y las Aldeas Virtuales. Los estudios geográficos y el retorno a la cultura”. Territorio y su Imagen. 1999, vol 2, pp. 1031 1039.

GALBRAITH, John Kenneth. Una sociedad mejor. Barcelona: Crítica, 1996.

GARCÍA BALLESTEROS, Aurora. "Nuevos espacios del consumo y exclusión social”. Anales de Geografía de la Universidad Complutense. 1998, $n^{\circ}$ 18, p. 47-63.

GÉS, Marcel. “La cultura telemática y el territorio”. La Factoría [en línea]. 1997, no. 2

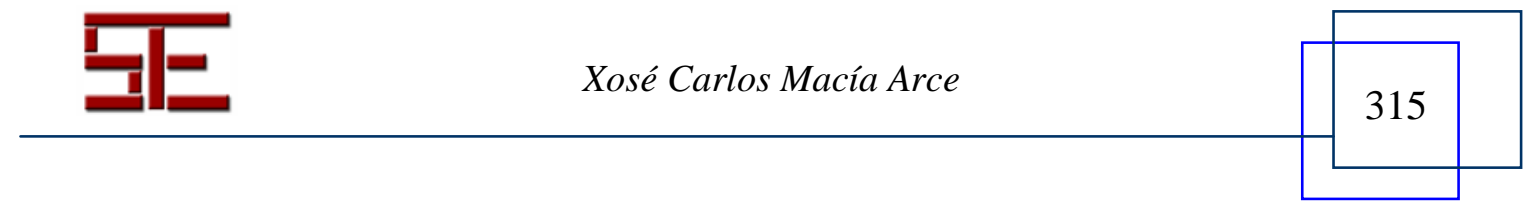




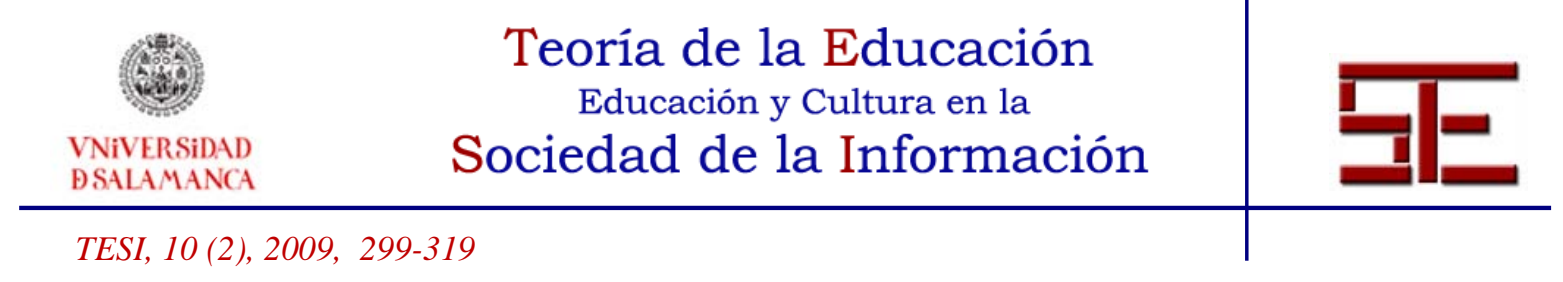

[ref. de 27 marzo 2003]. Disponible en Internet: http://www.lafactoriaweb.com/articulos/marcel2.htm

HARVEY, David. Espacios de esperanza. Madrid: Akal, 2007.

HARVEY, David. Social Justice and the City. Londres: Edward Arnold, 1973.

JOSPIN, L. "Preparar nuestra entrada en la Sociedad de la Información”. La Factoría [en línea]. 1997, no. 4 [ref. de 27 marzo 2003]. Disponible en Internet: http://www.lafactoriaweb.com/articulos/jospin4.htm

LÓPEZ TRIGAL, L.; BENITO DEL POZO, P. Geografía política. Madrid: Cátedra, 1999.

MÉNDEZ GUTIÉRREZ DEL VALLE, R. Geografía económica: la lógica espacial del capitalismo global. Barcelona: Ariel, 1997.

PARETO, Vilfredo. Manual de Economía Política. Ginebra: Droz, 1966.

PENA TRAPERO J. B. Problemas de la medición del bienestar y conceptos afines (Una aplicación al caso español). Madrid: Instituto Nacional de Estadística, 1977.

SCHULDT, Jurgen. “Capacidades y derechos”. ELPE [en línea]. 1997 [ref. de 20 de enero de 2001]. Disponible en Internet http://www.geocities.com/WallStreet/Floor/ 9680/senschuldt.htm

SEN, Amartya. Development as freedom. New York: Anchor, 2000.

SEN, Amartya. “El futuro del Estado del Bienestar”. La Factoría [en línea]. 1999, no. 8 [ref. de 27 marzo 2003]. Disponible en Internet: http://www.lafactoriaweb.com/articulos/amartya.htm

SEN Amartya. La calidad de vida. México D.F.: Fondo de Cultura Económica, 1996.

SEN Amartya. Nueva economía del bienestar. Escritos seleccionados. Valencia: Universidad de Valencia, 1995.

SEN Amartya. Elección colectiva y bienestar social. Madrid: Alianza, 1976.

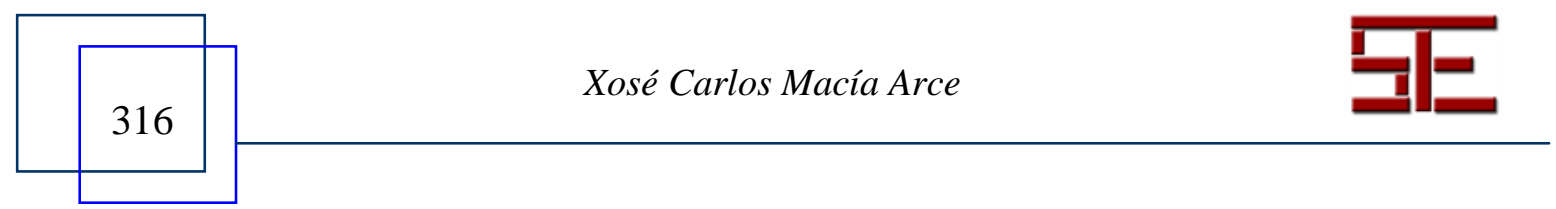




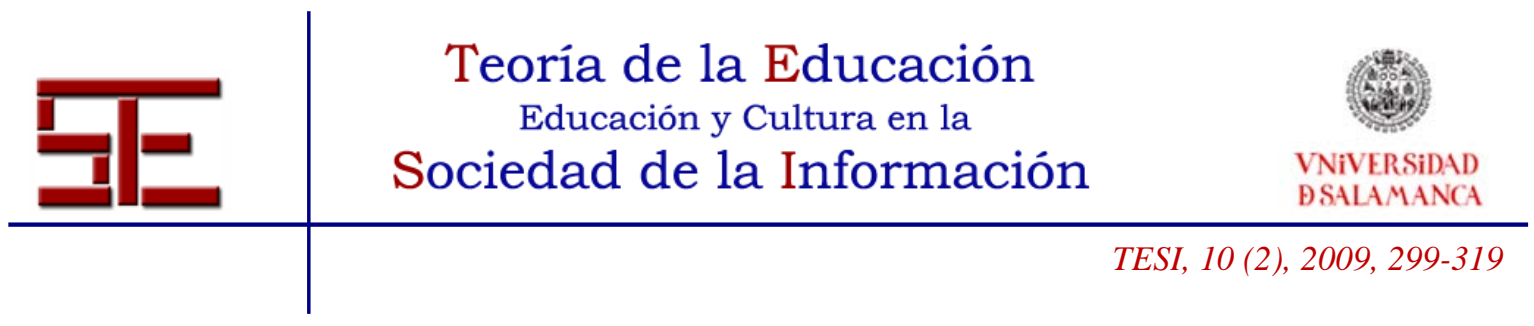

SETIÉN SANTAMARÍA, María Luisa. Indicadores sociales de Calidad de Vida. Un sistema de medición aplicado al País Vasco. Madrid: Siglo veintiuno de España, 1993.

SMITH, David. Geografía Humana. Barcelona: Oikos-Tau, 1980.

SMITH, Neil. Uneven Development: nature, capital and the production of space. Oxford: Blackwell, 1984.

TOURAINE, Alain. “La transformación de las metrópolis”. La Factoría [en línea]. 1998, no. 6 [ref. de 27 marzo 2003]. Disponible en Internet: http://www.lafactoriaweb.com/ articulos/touraine6.htm

VIVERET, Patrick. “La economía social en la Era de la Información”. La Factoría [en línea]. 2002, no. 16 [ref. de 27 marzo 2003]. Disponible en Internet: http://www.lafactoriaweb.com/articulos/viveret16.htm

\section{Notas}

1 Existen documentos oficiales que recogen estadísticas de múltiples indicadores y variables. Pueden consultarse al respecto Bilbao Metrópoli 30 (Ayuntamiento de Bilbao) y la Urban Audit (Comisión Europea).

Ambos documentos están disponibles en Internet (consultar bibliografía).

2 La tecnología es un medio que debe ser puesto al servicio de la comunidad (Jospin, 1997) y tener un buen acceso a Internet es calidad de vida (Casey, 2005).

3 En Bienestar social y calidad de vida, David Smith (1980) aboga por cruzar la frontera de otras disciplinas, contribuyendo así a la integración de la geografía en el conjunto de las ciencias sociales. Su punto de arranque comienza con la economía. Las teorías económicas sobre la oferta y la demanda o sobre la producción y el valor son incorporadas en la indagación geográfica.

4 Algunos investigadores denuncian que las ciudades europeas están conformando procesos de segregación urbana similares a los experimentados por las ciudades estadounidenses décadas atrás (Borja y Castells, 1997).

5 En el año 2000, las 500 personas más ricas del mundo acumulaban una riqueza total equivalente a la renta anual de la mitad de la población mundial (Dehesa Romero, 2000b).

6 David Smith nos recuerda incluso como Elliston-Allen y su Geografía de los gustos detecta las distintas preferencias de las sociedades.

7 Guillermo de la Dehesa recoge la localización geográfica como un factor relevante en la economía de los países (2000, pp. 55).

En la escala urbana, Manuel Castells en un estudio centrado en los Estados Unidos verifica como las pequeñas ciudades en regiones deprimidas tienden a ser más pobres que las grandes ciudades (1995, pp.

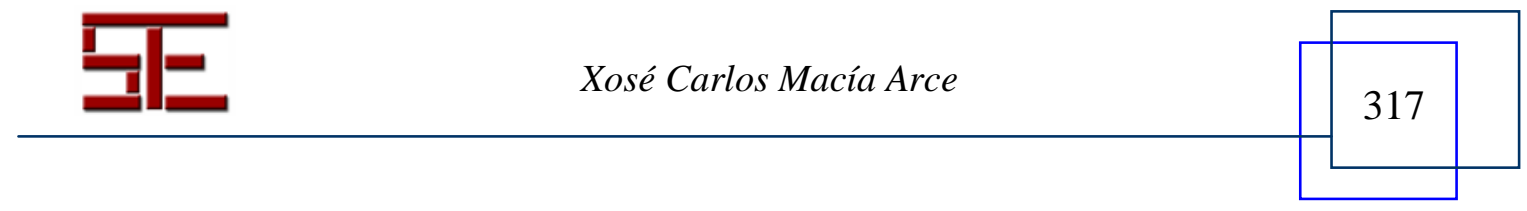




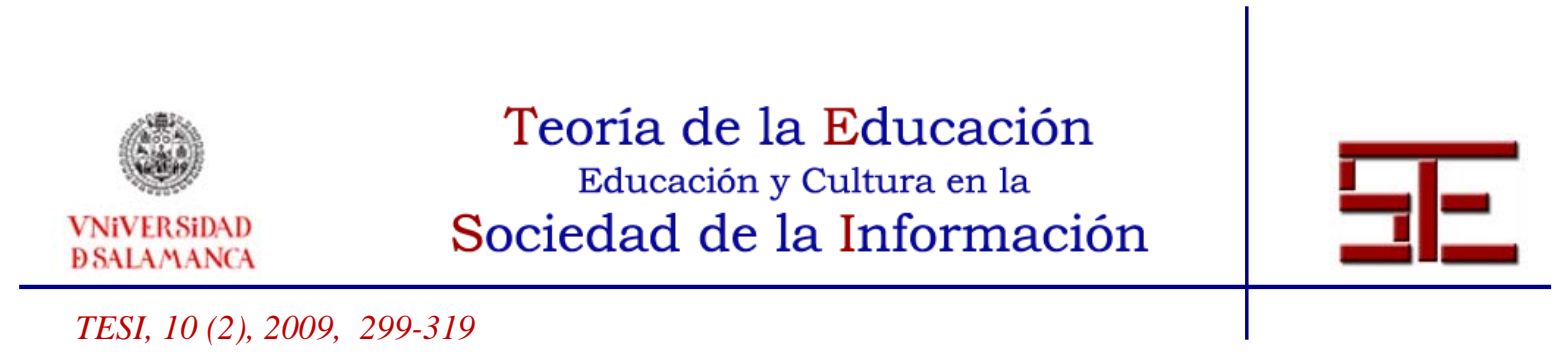

340). Las actividades económicas repercuten en gran medida en la calidad de vida de las personas. En este sentido, Ricardo Méndez (1997, pp. 315) sitúa el comercio como una actividad que de forma indiscutible influencia la vida de una población. No todos los espacios disponen del mismo despliegue en el sector terciario, por tanto nos encontramos una vez más con una connotación de relativismo cultural. 8 Presentó su tesis doctoral, La calidad de vida y su medida. Sistema de indicadores sociales para el País Vasco, en el año 1990, tomando como base un estudio sobre calidad de vida en el País Vasco.

9 Ver Pena Trapero, 1977.

10 Actualmente, la estadística informatizada permite desglosar y asignar valores numéricos a la información abstracta, con muy buenos resultados.

11 Ver teorías de Amartya Sen (1976), Vilfredo Pareto (1966), John Kenneth Arrow (1970), Rawles y Esping Andersen (2001).

12 Paul Samuelson está considerado como uno de los autores clave en la economía neoclásica, con aportaciones muy importantes en economía matemática y en teoría del equilibrio general.

13 Su crítica, centrada en los Estados Unidos, puede extrapolarse en gran medida a las circunstancias que caracterizan ciertas naciones de la Unión Europea, como podría ser el caso del Reino Unido (Estruch Manjón, 2002).

14 Se refiere a las capas sociales más empobrecidas en el Tercer Mundo, pero también al denominado Cuarto Mundo, es decir, a los ciudadanos más desfavorecidos en los países occidentales.

15 Este principio plantea conocer si las circunstancias pueden justificar un trato diferencial (David Smith, 1980).

16 Idea fundamental para entender el pensamiento ético de Amartya Sen, bien interpretada por Jurgen Schuldt en su artículo “Capacidades y derechos”, ELPE, 1997.

17 SEN, Amartya: “Nueva economía del bienestar. Escritos seleccionados”, Universidad de Valencia, Valencia, 1995.

SEN, Amartya: "La calidad de vida”, Fondo de Cultura Económica, México D.F., 1996.

SEN, Amartya: “Elección colectiva y bienestar social”, Alianza, Madrid, 1976.

SEN, Amartya: “El futuro del Estado del Bienestar”. La Factoría [en línea]. 1999.

${ }_{18}$ El marco teórico y los razonamientos matemáticos de Amartya Sen son muy complejos y no son pocas las ocasiones en las que su lenguaje resulta "indescifrable", sobre todo para los que compartimos una formación humanista. No obstante, y a pesar de estos inconvenientes, es posible obtener conclusiones relevantes.

19 Economista italiano (1848-1923). Al estudiar la distribución de la riqueza y las rentas estableció la llamada "Ley de Pareto" según la cual la desigualdad económica es inevitable en cualquier sociedad.

20 Economista estadounidense (1921-). Su tesis doctoral “Social Choice and Individual Values" (1970) supuso una revolución teórica. Obtuvo el premio Nobel de Economía en 1972, compartido con el británico John R. Hicks (profesor en la London School of Economics entre 1926 y 1935).

21Formalmente denominado Teorema General de la Posibilidad.

22 Esta suposición es quizás un tanto exagerada porque los teóricos que defienden el relativismo cultural en ningún caso manifestaron están a favor de las desigualdades sociales.

23 La democracia es el único sistema político que permite que la comunidad seleccione sus preferencias y, en este sentido, retoman, entre otros teóricos, las posturas de Kenneth Arrow y Amartya Sen.

Para citar la presente editorial puede utilizar la siguiente referencia:

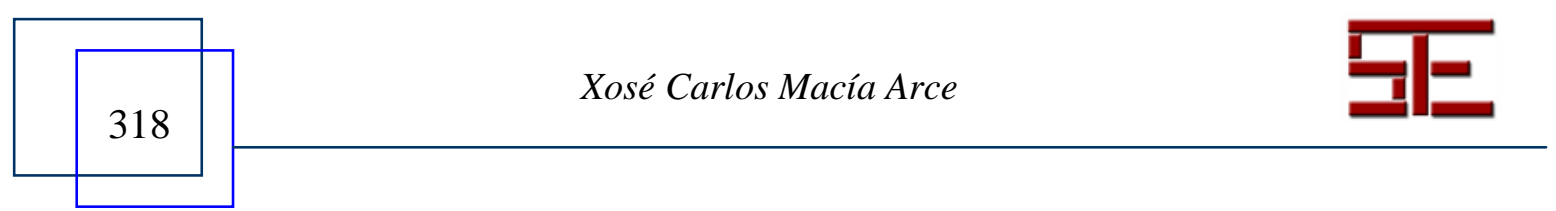




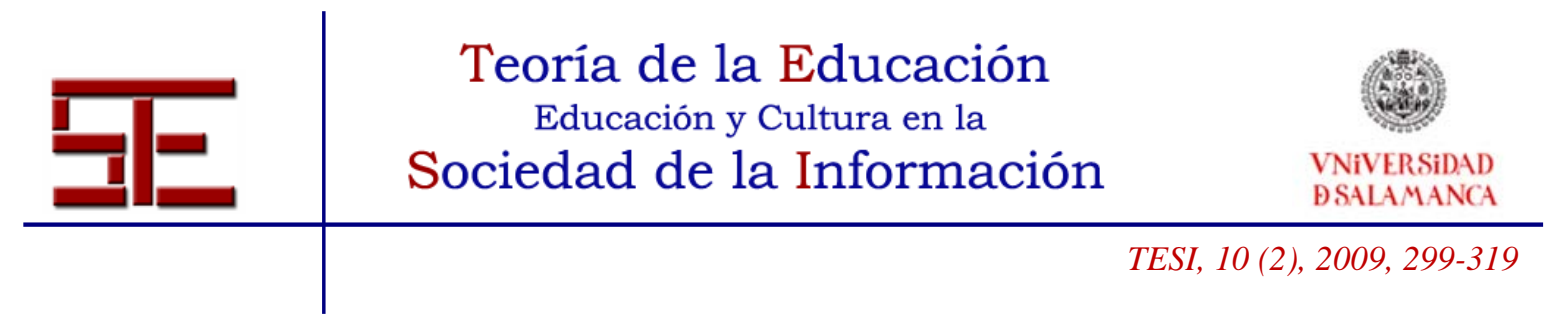

Macia. M. (2009). Consideraciones teóricas sobre el concepto calidad de vida en la sociedad de la información, en Ortega Sánchez, I. y Ferrás Sexto, C. (Coord.) Alfabetización Tecnológica y desarrollo regional. Revista Electrónica Teoría de la Educación: Educación y Cultura en la Sociedad de la Información. Vol. 10, n ${ }^{0} 2$. Universidad de Salamanca, pp. 299-319 [Fecha de consulta: dd/mm/aaaa].

http://campus.usal.es/ revistas_trabajo/index.php/revistatesi/article/view/7518/7551

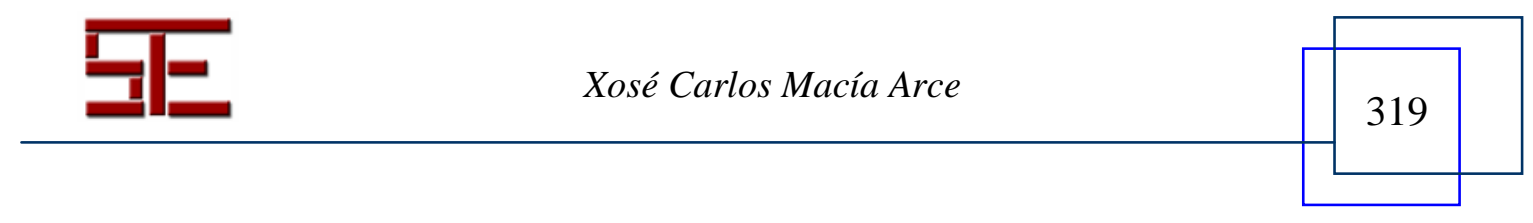

